\title{
STRATEGI PENGEMBANGAN DAYA TARIK UNTUK MENDUKUNG PROMOSI DESA WISATA PUSPOARDI YOGYAKARTA
}

\author{
Atun Yulianto ${ }^{1}$, Emmita Devi Hari Putri ${ }^{2}$ \\ ${ }^{1}$ Universitas Bina Sarana Informatika, atun.aty@bsi.ac.id, \\ ${ }^{2}$ Universitas Bina Sarana Informatika, emmita.evr@bsi.ac.id
}

\begin{abstract}
ABSTRAK
Belum banyaknya masyarakat mengenal dan beminat untuk berkunjung ke desa wisata Puspoardi dengan ikon-ikon wisatanya yang menarik. Hal ini berdampak pada menurunnya semangat pengelola untuk mengembangkan destinasi agar lebih optimal. Tujuan penelitian ini adalah untuk merumuskan alternatif strategi pengembangan daya tarik yang mendukung kegiatan promosi untuk mendatangkan wisatawan ke desa wisata Puspoardi. Metode penelitian dalam riset ini adalah diskriptif kualitatif yang didukung dengan metode SWOT analysis untuk merumuskan strategi sesuai tujuan penelitian. Hasil penelitian berdasarkan metode analysis yang digunakan menunjukkan bahwa perbandingan bobot score antara kekuatan dan kelemahan adalah kelemahan lebih besar dari pada kekekuatan. Sedangkan perbandingan antara bobot score peluang dan ancaman adalah peluang lebih besar dari pada ancaman. Dengan hasil analysis ini strategi pengembangan daya tarik wisata yang relevan untuk diterapkan pada desa wisata Puspoardi adalah dengan memanfaatkan kelemahan dan peluang (weakness and oppurtinities), dengan rumusan strategi antara lain : menjalin kerjasama dengan pihak lain seperti perguruan tinggi untuk mendapatkan pendampingan dan pelatihan dalam menyusun strategi informasi dan promosi dengan tehnologi yang ada saat ini, meningkatkan peran serta masyarakat khususnya pengelola desa wisata untuk mengembangkan alat promosi yang relevan dalam versi cetak maupun online, memanfaatkan dukungan pemerintah untuk pembangunan fasilitas pokok yang belum tersedia.
\end{abstract}

Kata Kunci : Strategi, daya tarik, promosi, wisata

\begin{abstract}
Not many people know and are interested in visiting the Puspoardi tourist village with its attractive tourist icons. This has an impact on decreasing the enthusiasm of managers to develop destinations to be more optimal. The purpose of this research is to formulate an alternative strategy to develop attractiveness that supports promotional activities to bring tourists to the Puspoardi tourist village. The research method in this research is a qualitative descriptive supported by the SWOT analysis method to formulate strategies according to the research objectives. The results of the study based on the analysis method used indicate that the comparison of the weight score between strengths and weaknesses is weakness greater than strength. While the comparison between the weight of the opportunity and the threat score is a greater opportunity than the threat. With the results of this analysis, the strategy for developing a tourist attraction that is relevant to the Puspoardi tourist village is to take advantage of weaknesses and opportunities, with strategic formulations including: collaborating with other parties such as universities to get assistance and training in preparing information and promotion strategies with existing technology, increase community participation, especially tourism village managers to develop relevant promotional tools in print and online versions, take advantage of government support for the construction of basic facilities that are not yet available.
\end{abstract}

Keywords: Strategy, Attraction, Promotion, Tourism

ISSN: 2355-6587, e-ISSN: 2528-2220

http://ejournal.bsi.ac.id/ejurnal/index.php/jp 


\section{PENDAHULUAN}

Desa wisata merupakan salah satu unsur penting dalam pembangunan sektor pariwisata yang menyajikan pelayanan dan fasilitas yang dapat dinikmati oleh wisatawan berbasis pemberdayaan masyarakat. Pemberdayaan masyarakat menurut Hadiwijoyo (2012) dalam Istifazhuddin dkk (2016), merupakan proses perubahan struktur yang harus muncul dari lapisan masyarakat, dilakukan sendiri oleh masyarakat, dan hasilnya juga ditujukan untuk kesejahteraan masyarakat itu sendiri. Desa wisata Puspoardi merupakan salah satu desa wisata yang terletak di dusun Talunombo, Desa Sidomulyo, Kecamatan Pengasih, Kabupaten Kulonprogo yang dirintis sejak tahun 2014. Desa ini berpenduduk sebanyak 6.032 jiwa dan 1.474 KK. Desa Sidomulyo memiliki ketinggian tanah 84-484 mdpl dengan topografi berupa dataran tinggi dengan suhu udara ratarata $28^{\circ} \mathrm{C}$. Desa Sidomulyo terbagi ke dalam 13 pedukuhan dengan $27 \mathrm{RW}$ dan 56 RT. Sarana Pendidikan terdiri dari 3 TK, 5 SD dan 2 SMP. Sarana peribadatan terdapat 22 masjid, 8 mushola, dan 2 kapel 2. Desa sidomulyo merupakan salah satu desa di Kecamatan Pengasih yang tidak memiliki pasar desa, dengan lahan pertanian sawah dan ladang seluar 846,8850 ha.

Potensi wisata yang dimiliki Puspoardi meliputi; wisata alam, wisata budaya, wisata religi, wisata kuliner, wisata herbal, wisata pendidikan, dan wisata buah. Potensi utama yang menjadi icon Puspoardi berupa tiga puncak pegunungan yang menawarkan pemandangan alam sangat elok dengan panorama sunset dan kolam embung yang dibangun diatas puncak bukitnya. Berbagai kesenian tradisional dan upacara adat masih terpelihara dengan baik sebagai event tahunan menjadi daya tarik wisata budaya. Makanan khas yang dimiliki berupa olahan Geblek dan Tempe Benguk, yang menjadi daya tarik tersendiri bagi wisatawan. Mayoritas penduduk bermata pencaharian sebagai petani yang membudidayakan tanaman local seperti ketela, tanaman herbal dan buah-buahan tropis. Daya tarik wisata lain, yang dapat dinikmati pengunjung adalah adanya petilasan Damarwulan, tokoh legenda cerita rakyat Jawa yang berada di desa wisata Puspoardi. Desa wisata Puspaardi mempunyai potensi sumber daya alam yang cukup menarik dengan keindahan perbukitannya. Namun demikian belum banyak masyarakat mengetahui dan tertarik berkunjung untuk menikmati keindahannya.

Desa wisata Puspoardi dikelola masyarakat yang tergabung dalam kelompok sadar wisata rintisan dibawah tatakelola pemerintah desa Sidomulyo. Pengelolan yang dilakukan belum maksimal, hal ini terkait dengan kesadaran masyarakat untuk terlibat dalam pengelolaan wisata Puspoardi masih kurang, dengan pertimbangan belum banyak pengunjung. Permasalahan yang sangat mendesak dan selama ini masih membutuhkan jalan keluar adalah bagaimana mengembangkan daya tarik wisatanya sebagai penopang kegiatan pemasaran yang relevan, sehingga dapat menarik dan mendatangkan banyak wisatawan. Hal ini sesuai dengan pendapat dari Damanik (2013), yang menyatakan bahwa kelemahan dalam pemberdayaan komunitas masyarakat lokal dalam mengembangkan usahanya adalah jaringan untuk pemasaran maupun relasi. Oleh karena itu pengembangan daya tarik wisata dibutuhkan untuk mendukung program pemasaran yang tepat oleh pengelola desa wisata Puspoardi, sebagai upaya menarik calon pengunjung. Oleh karena itu, penelitian ini menitikberatkan tujuan penelitian pada pengembangan daya tarik untuk mendukung proses promosi pemasaran, sehingga dapat meningkatkan pengetahuan, kesadaran dan kunjungan masyarakat ke desa wisata Puspoardi. 


\section{KAJIAN LITERATUR \\ Daya Tarik Wisata}

Daya Tarik Wisata merupakan semua hal yang memiliki keunikan, keindahan, dan nilai yang berupa berbagai macam kekayaan alam, budaya, dan hasil buatan manusia yang menjadi sasaran atau tujuan dari kunjungan wisatawan (UU No.10 Tahun 2009).

Daya tarik wisata menjadi bagian tidak terpisahkan dalam proses pemasaran karena akan memudahkan pemasar dalam mempengaruhi persepsi calon wisatawan. Dalam penelitian yang dilakukan Kartika dkk (2018), startegi pengembangan daya tarik wisata dapat dioptimalkan pada kegiatan atau atraksi wisata dan promosinya. Dalam melakukan pengembangan daya tarik wisata seperti yang diuraikan dalam kesimpulan penelitian yang dilakukan Nainggolan \& Kampana (2015), strategi yang digunakan untuk pengembangan objek wisata meliputi memberdayakan masyarakat baik dari segi peluang kerja dan pemeliharaan lingkungan serta menambahkan fasilitas-fasilitas pendukung agar menjadi daya tarik bagi wisatawan untuk berkunjung. Sedangkan menurut hasil penelitian dari Wilopo dan Hakim (2017), disebutkan dalam hasil penelitian bahwa strategi pengembangan destinasi wisata dapat dilakukan antara lain dengan menyusun paket wisata, mengembangkan image destinasi, mengembangkan promosi cetak dan online, mengikuti event kegiatan, aksesbilitas, amenitas, fasilitas dan sumber daya manusia pengelola.

Jadi dari hasil penelitian beberapa sumber dapat disimpulkan bahwa strategi pengembangan dalam aspek daya tarik wisata dapat dilakukan dengan optimalisasi atraksi wisata, promosi ofline dan online, sumber daya manusia, pemeliharaan lingkungan, paket wisata, image, event, aksesbilitas, amenitas dan fasilitas.

Strategi Dan Bauran Pemasaran

Menurut Kotler \& Amstrong (2012), Strategi pemasaran merupakan logika pemasaran dimana suatu perusahaan memiliki ekspektasi atau harapan untuk dapat menciptakan produk yang memiliki nilai bagi pelanggan dan dapat menciptakan hubungan timbal-balik yang menguntungkan dengan pelanggan. Dalam penelitian yang dilakukan oleh Mahendrayani dan Suryawan (2018) tentang Strategi Pemasaran Daya Tarik Wisata Untuk Meningkatkan Jumlah Kunjungan Wisatawan, dengan menggunakan metode SWOT mendapatkan hasil penelitian bahwa strategi pemasaran yang dilakukan untuk meningkatkan jumlah kunjungan wisatawan ke daya tarik wisata seperti Sangeh adalah dengan menciptakan branding untuk daya tarik wisata tersebut. Upaya untuk menciptakan branding yang paling umum digunakan berbagai organisasi adalah dengan penyelenggaraan event kegiatan yang dapat menghadirkan banyak pengunjung.

Pemasaran pariwisata pada dasarnya dapat ditekankan pada siapa segmen pasar yang sebetulnya dikuasai dan bagaimana bentuk perilaku mereka (Damanik \& Weber, 2006). Pemasar dapat memfokuskan tindakan pada cara mengkomunikasikan nilai jasa wisata yang ditawarakan kepada masyarakat luas dengan memunculkan keunggulan dan perberbedaanya dengan tempat wisata lain. Media promosi konvensional dapat diterapkan dalam menarik minat calon wisatawan, walaupun tidak selamanya dapat digunakan untuk produk pariwisata minat khusus, sehingga perlu mengkombinasikan dengan media promosi elektornik. Dalam aspek pemasaran jasa unsur promosi merupakan salah satu bagian dari bauran pemasaran yang harus ada untuk mendukung bauran yang lain. Menurut Kotler and Amstrong (2012), bauran pemasaran jasa dapat terdiri dari $7 \mathrm{P}$, yaitu product, price, place, promotion, physical Evidence, People dan Procees. Ketujuh unsur ini harus terpenuhi agar proses pemasaran jasa dapat berjalan 
sesuai kebutuhan, termasuk didalamnya jasa wisata.

Bauran pemasaran jasa yang dimiliki suatu destinasi wisata tentunya akan menjadi faktor internal untuk mengkomunikasikan daya Tarik (potensi) yang dimiliki kepada masayrakat luas. Adanya factor internal ini tentu saja dalam proses komunikasinya akan dipengaruhi pula oleh factor yang ada diluar organisasi atau eksternal factor. Dalam factor eksternal menurut Utama \& Mahadewi (2012), dapat meliputi perkembangan tehnologi, keamanan, lingkungan sekitar, kebijakan pemerintah, social budaya masyarakat, ekonomi suatu negara dan pengunjung wisata itu sendiri.

\section{Media Promosi}

Pengertian promosi menurut Kotler (2000), merupakan bagian dari proses strategi pemasaran sebagai salah satu cara untuk berkomunikasi dengan pasar menggunakan komposisi bauran promosi atau promotion mix yang dimiliki perusahaan. Sedangkan menurut Sistaningrum (2002), promosi merupakan kegiatan perusahaan dalam upayanya mempengaruhi konsumen aktual maupun potensial agar konsumen yang dituju bersedia membeli produk yang ditawarkan saat ini atau dimasa yang akan datang. Dari kedua definisi promosi diatas dapat diartikan bahwa promosi merupakan proses kegiatan perusahaan dalam upayanya mengkomunikasikan produk yang dimiliki kepada calon konsumen sehingga mau membeli produk yang ditawarakannya.

Alat-alat promosi bidang kepariwisataan yang dapat dijadikan alternatif untuk mengkomunikasikan produk kepada calon pengunjung saat ini telah berkembang mengikuti kemajuan tehnologi. Disamping media promosi konvensional yang banyak digunakan pada masa lalu seperti brosure, spanduk, baliho, majalah dan sejenisnya, kini telah berkembang media promosi modern dengan memanfaatkan jaringan internet

untuk mengkomunikasikan produk kepada calon konsumen. Hapir seluruh masyarakat dunia kini telah terhubung keinternat dan banyak meghabiskan waktu untuk berselancar didunia maya. Hal ini diperkuat hasil penelitian yang dilakukan Adiyanto dan Supriatna (2018), dalam penelitiannya dengan tema "Analisis Strategi Promosi Dalam Pengembangan Pariwisata Di Kabupaten Lebak Banten" menyebutkan bahwa promosi oleh Dinas Pariwisata dan Ekonomi Kreatif dengan ikut serta dalam kegiatan event festival atau pameran pariwisata masih lebih efektif dibandingkan dengan media promosi media cetak seperti brosur, pamflet, dan media cetak lainnya. Hal ini sebagai efek dari kecenderungan masyarakat yang lebih banyak mengakses internet dibandingkan melihat media-media promosi yang berbentuk konvensional.

Dalam penelitian oleh Setiawan dan Hamid (2014), dengan tema "Strategi Promosi Dalam Pengembangan Pariwisata Lokal di Desa Wisata Jelekong" menyebutkan bahwa alat-alat promosi yang digunakan pengelola desa wisata merupakan kombinasi promosi konvensioanl dan modern dengan media seperti word of mouth, public relations, personal selling, event, eksibisi, merchandise, publikasi, dan website internet. Dengan prioritas utama alat promosi adalah event kegiatan dan public relations. Jadi untuk mengembangkan media promosi sesuai dengan perkembangan jaman, pengelola destinasi wisata dapat memfokuskan media promosi yang bersifat digital melalui internet seperti media social dan memperkuat triger kunjungan wisatawan dengan penyelenggaraan event pariwisata.

\section{Desa Wisata}

Desa wisata adalah kelompok atau komunitas masyarakat yang meliputi penduduk yang ada disuatu lingkup wilayah tertentu yang saling berinteraksi dibawah pengelolaan bersama dengan mengedepankan kepedulian dan kesadaran untuk memberdayakan potensi yang ada sesuai 
kemampuan masing-masing secara kondusif bagi tumbuh dan kembang periwisata diwilayahnya (Setiyadi, 2019). Jadi dalam desa wisata diciptakan dengan mengerahkan masyarakat untuk berperan aktif menjadi pelaku langsung dalam upaya mengelolan dan mengembangakan potensi pariwisata yang ada di wilayahnya. Konsep pengembangan desa wisata tidak saja dengan adanya sebuah objek wisata namum membutuhkan peranserta keterlibatan masayarakat secara bersama-sama membangun komunitas meningkatkan pemahaman dan pengelolaan potensi wisata yang ada diwilayahnya baik dari sisi atraksi, amenitas dan aksesbilitas,

\section{METODE PENELITIAN}

Penelitian ini menggunakan metode diskriptif kualitatif dengan mengabil objek penelitian di Desa Wisata Puspoardi Desa Sidomulyo, Kecamatan Pengasih, Kabupaten Kulonprogo. Pengumpulan data dilakukan sejak bulan September 2020 sampai Nopember 2020 dengan melakukan survey, observasi dan kegiatan pendukung lainnya seperti dokumentasi dan studi pustaka. Sumber informasi utama adalah bapak Kabul selaku Lurah Desa Sidomulyo, Pengasih Kulon progo. Tehnik analisis data dalam penelitian ini menggunakan SWOT analysis. Berdasarkan data-data yang diperoleh dilajutkan dengan membuat klasifikasi data untuk menentukan kelompok faktor internal dan eksternal sebagai dasar indentifikasi kekuatan, kelemahan, peluang atau ancaman sebelum disusun kedalam matrik IFAS dan EFAS. Tahap terakhir adalah mengambil keputusan terhadap strategistrategi yang terbaik menggunakan matriks QSPM (Quantitative Strategic Planning Matrix).

\section{PEMBAHASAN}

Desa wisata Puspoardi memiliki ikon yang berupa puncak bukit yang berada di dusun Talunombo, dimana pengunujung dapat menikmati atraksi wisata yang ditawarkan meliputi gardu pandang, spot foto, bentang alam, tanaman hias, tanaman keras dan embung diatas bukit. Penelitian ini menghasilkan data hasil interview dari pengelola yang diwakili langsung oleh lurah desa Sidomulyo bapak Kabul, menunjukkan bahwa pemasaran desa wisata Puspoardi masih terbatas pada penyelenggaraan event budaya seperti pentas jathilan, wayang kulit dan orkes dangdut. Upaya ini dimaksudkan agar supaya Puspoardi dapat lebih dikenal masyarakat luas.

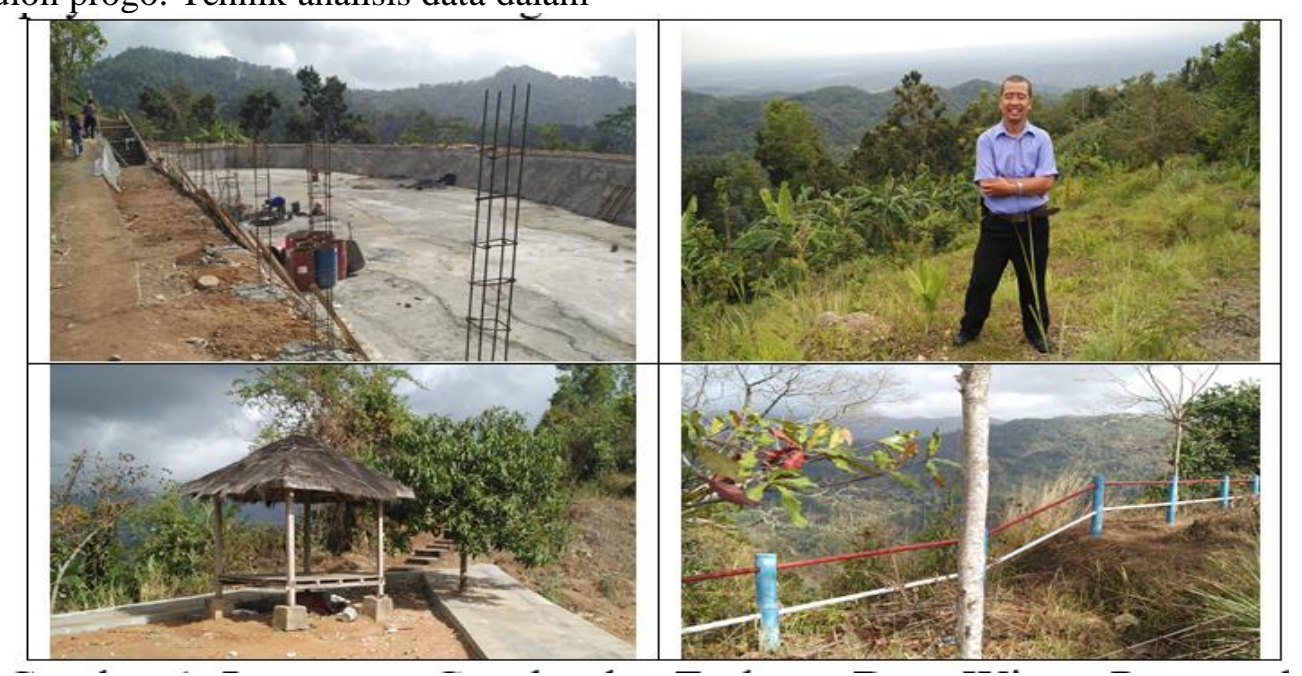

Gambar 1. Lanscapé, Gazebo dan Ëmbung Desa Wisata Puspoärdi

Sumber : Dokumentasi Penelitian (2019)

ISSN: 2355-6587, e-ISSN: 2528-2220

http://ejournal.bsi.ac.id/ejurnal/index.php/jp 
Kegiatan dan sarana wisata yang disedakan sudah cukup memadai mulai dari wisata alam, budaya, kuliner dan buah, namun demikian masyarakat belum banyak yang mengenal dan tertarik berkunjung didesa wisata Puspoardi. Oleh karena itu dibutuhkan perumusan strategi pengembangan media promosi yang paling mendesak untuk diterapkan dalam waktu pendek maupun jangka panjang.
Strategi untuk mengembangkan media promosi pemasaran sebagaimana tujuan penelitian ini maka, dapat dirumuskan dengan membuat analisis yang berupa matrik SWOT dimulai dengan mengidentifikasi variabel interal dan eksternal dalam matrik Internal Strategic Factor Analysis Summary Matrix (IFAS) dan External Strategis Factor Analysis Summary (EFAS) sebagai berikut:

Tabel 1 Internal Strategic Factor Analysis Summary Matrix (IFAS)

\begin{tabular}{|c|c|c|c|c|}
\hline NO & Faktor strategis internal & Bobot $(\%)$ & Rating & Skor \\
\hline \multicolumn{5}{|c|}{ Kekuatan (strenghts) : } \\
\hline 1 & Kondisi landscape yang indah & 6.12 & 3.92 & 0.24 \\
\hline 2 & Adanya embung yang unik diatas bukit & 5.94 & 3.90 & 0.23 \\
\hline 3 & Sewa gasebo dan spot foto masih gratis & 5.79 & 3.87 & 0.22 \\
\hline 4 & Keanekaragaman tanaman keras & 5.63 & 3.51 & 0.20 \\
\hline 5 & Tiket masuk masih gratis & 4.86 & 3.50 & 0.17 \\
\hline 6 & $\begin{array}{l}\text { Penyampaian informasi dan promosi melalui } \\
\text { pendekatan event budaya }\end{array}$ & 4.83 & 3.48 & 0.17 \\
\hline 7 & Keramahtamahan petugas pengelola sangat baik & 4.72 & 3.45 & 0.16 \\
\hline 8 & Proses penyambutan kedatangan wisatawan baik & 4.54 & 2.86 & 0.13 \\
\hline 9 & Penampilan petugas pengelola cukup baik & 4.49 & 2.71 & 0.12 \\
\hline 10 & Tarif parkir terjangkau & 4.47 & 2.10 & 0.09 \\
\hline \multicolumn{2}{|r|}{ Kelemahan (weakness) : } & & & - \\
\hline 1 & $\begin{array}{l}\text { Penyampaian informasi melalui media online } \\
\text { kurang }\end{array}$ & 6.84 & 3.97 & 0.27 \\
\hline 2 & $\begin{array}{l}\text { Penyampaian informasi melalui media cetak } \\
\text { kurang }\end{array}$ & 6.57 & 3.94 & 0.26 \\
\hline 3 & $\begin{array}{l}\text { Jalur/rute yang dilalui menuju objek wisata kurang } \\
\text { lebar }\end{array}$ & 5.94 & 3.85 & 0.23 \\
\hline 4 & $\begin{array}{l}\text { Fasilitas pendukung yang tersedia (toilet) belum } \\
\text { ada }\end{array}$ & 5.85 & 3.82 & 0.22 \\
\hline 5 & Program pelatihan bagi pengelola masih kurang & 4.81 & 3.75 & 0.18 \\
\hline 6 & Peta jalan pengunjung didalam lokasi belum ada & 4.75 & 2.77 & 0.13 \\
\hline 7 & Pelayanan yang diberikan kurang maksimal & 3.58 & 2.04 & 0.07 \\
\hline 8 & Tempat parkir masih terbatas & 3.55 & 1.84 & 0.07 \\
\hline 9 & $\begin{array}{l}\text { Kemampuan SDM perlu ditingkatkan baik } \\
\text { pengelolaan maupun berkomunikasi dalam bahasa } \\
\text { asing }\end{array}$ & 2.97 & 1.71 & 0.05 \\
\hline 10 & Perlu keberanian untuk mencapai lokasi & 1.90 & 1.52 & 0.03 \\
\hline 11 & Lokasi berada diatas perbukitan & 1.85 & 1.31 & 0.02 \\
\hline
\end{tabular}

Sumber : Hasil Penelitian (2020)

Skor dari Matrik IFAS pada tabel internal yang dikalikan dengan hasil diperoleh dari hasil rata-rata rata-rata rating masing-masing indikator pembobotan masing-masing indikator internal, maka didapatlah skor untuk

ISSN: 2355-6587, e-ISSN: 2528-2220

http://ejournal.bsi.ac.id/ejurnal/index.php/jp 
masing-masing indikator internal. Setelah itu skor dari seluruh indikatorindikator internal harus dijumlahkan dengan cara menjumlahkan skor dari indikator pertama sampai dengan indikator terakhir untuk memperoleh hasil skor lingkungan internal. Hasil skor dari matrik IFAS pada Tabel 1 diatas adalah 3,28. Skor tertinggi pada faktor internal adalah: kurangnya penyampaian informasi melalui media online sebesar 0,27 yang merupakan bagain dari kelemahan, sedangkan pada kekuatan skor tertinggi didapat dari kondisi lanscape dari destinasi dengan nilai score 0,24 dimana score ini sebesarnya masih kalah tinggi dari score kelemahan pada faktor penyampaian informasi melalui media cetak yang juga kurang, dengan besar score 0,26. Artinya antara score kekuatan dan kelemahan perbandingannya adalah score kelemahan lebih besar dari pada score kekuatannya.

Tabel 2 External Strategis Factor Analysis Summary (EFAS)

\begin{tabular}{|c|c|c|c|c|}
\hline NO & Faktor strategis internal & $\begin{array}{c}\text { Bobot } \\
(\%)\end{array}$ & Rating & Skor \\
\hline \multicolumn{5}{|c|}{ Peluang (opportunities) : } \\
\hline 1 & $\begin{array}{l}\text { Peran serta masyarakat tinggi dalam pengembangan } \\
\text { destinasi }\end{array}$ & 10.94 & 3.56 & 0.39 \\
\hline 2 & $\begin{array}{l}\text { Belum menerapan teknologi informasi dalam promosi } \\
\text { dan pengelolaan }\end{array}$ & 10.65 & 3.27 & 0.35 \\
\hline 3 & Didukung pemerintah desa dalam pengembangannya & 9.58 & 3.21 & 0.31 \\
\hline 4 & $\begin{array}{l}\text { Masih membutuhkan sumber daya manusia yang } \\
\text { profesional }\end{array}$ & 9.42 & 2.54 & 0.24 \\
\hline 5 & Mendapatkan bantuan pemerintah secara insidental & 8.46 & 2.47 & 0.21 \\
\hline 6 & $\begin{array}{l}\text { Masyarakat berperan aktif dalam pengawasan objek } \\
\text { wisata }\end{array}$ & 7.83 & 2.33 & 0.18 \\
\hline 7 & $\begin{array}{l}\text { Lokasi objek wisata ditempat yang jauh dari keramaian } \\
\text { kota }\end{array}$ & 5.11 & 1.97 & 0.10 \\
\hline 8 & Pemandangan alam sekitar sangat menarik & 4.48 & 1.74 & 0.08 \\
\hline 9 & Pengunjung dari berbagai kalangan mayarakat lokal & 3.45 & 1.58 & 0.05 \\
\hline \multicolumn{2}{|r|}{ Ancaman (threats) : } & \multirow[b]{2}{*}{7.85} & \multirow[b]{2}{*}{3.68} & \multirow{2}{*}{$\begin{array}{c}- \\
0.29\end{array}$} \\
\hline 1 & Motivasi pengunjung masih kurang & & & \\
\hline 2 & $\begin{array}{l}\text { Keamanan pengunjung perlu ditingkatkan dengan } \\
\text { pagar pengaman }\end{array}$ & 6.47 & 3.72 & 0.24 \\
\hline 3 & Keamanan lokasi objek wisata perlu ditingkatkan & 5.32 & 3.51 & 0.19 \\
\hline 4 & $\begin{array}{l}\text { Kondisi ekonomi regional dan nasional belum } \\
\text { mendukung akibat pandemi covid } 19\end{array}$ & 5.23 & 3.26 & 0.17 \\
\hline 5 & $\begin{array}{l}\text { Kondisi ekonomi global belum mendukung karena } \\
\text { pandemi covid } 19\end{array}$ & 5.21 & 3.22 & 0.17 \\
\hline & Total Score & 100.00 & & 2.96 \\
\hline
\end{tabular}

Sumber : Hasil Penelitian (2020)

Skor dari matrik EFAS pada tabel 2.

diperoleh dari hasil rata-rata

pembobotan masing-masing indikator

eksternal yang dikalikan dengan hasil rata-rata rating masing-masing indikator eksternal, maka didapatlah skor untuk masing-masing indikator eksternal. Setelah itu skor dari seluruh indikatorindikator eksternal harus dijumlahkan dengan cara menjumlahkan skor dari

indikator pertama sampai dengan indikator terakhir untuk memperoleh hasil skor lingkungan eksternal. Hasil skor dari matrik EFAS pada Tabel 2 di atas adalah 2.96. Skor tertinggi pada faktor eksternal adalah: peran masyarakat tinggi dalam pengembangan destinasi yaitu sebesar 0,39 yang merupakan bagain dari peluang sedangkan pada ancaman skor tertinggi 
didapat dari motivasi pengunjung untuk mendatangi destinasi masih rendah dengan nilai score 0,29 dimana score ini sebesarnya masih kalah tinggi dari score peluang pada faktor penerapan tehnologi informasi dalam promosi dan pengelolaan dengan besar score 0,35. Artinya antara score peluang dan ancaman perbandingannya adalah score peluang lebih besar dari pada score ancaman.

Jadi setelah diketahui bahwa perbandingan score antara kekuatan dan kelemahan adalah kelemahan lebih besar dari pada kekekuatan. Sedangkan perbandingan antara score peluang dan ancaman adalah peluang lebih besar dari pada ancaman. Artinya strategi pengembangan daya tarik wisata yang paling mungkin diterapkan pada desa wisata Puspoardi adalah dengan memanfaatkan kelemahan dan peluang (weakness and oppurtinities), dalam hal ini disebut dengan strategi W-O. Dengan besarnya nilai IFAS $=3,28$ dan EFAS $=2,96$, maka dapat ditentukan posisi organisasi dalam strategy pengembangan daya tarik desa wisata Puspoardi melalui tabel sebagai berikut:

Table 3. Posisi Organisasi Dalam Matriks Internal-Eksternal Desa Wisata Puspoardi

\begin{tabular}{|c|c|c|c|c|}
\hline & \multicolumn{4}{|c|}{ TOTAL NILAI IFAS } \\
\hline \multirow{6}{*}{ 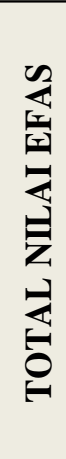 } & 4 & 3 & 2 & 1 \\
\hline & & $\mathrm{I}$ & II & III \\
\hline & 3 & $\begin{array}{c}\text { Tumbuh dan bina (konsentrasi } \\
\text { via integrasi vertical) }\end{array}$ & $\begin{array}{c}\text { Tumbuh dan bina (konsentrasi } \\
\text { via integrasi horizontal) }\end{array}$ & $\begin{array}{c}\text { Pertahankan dan pelihara } \\
\text { (pertumbuhan berputar) }\end{array}$ \\
\hline & & $\begin{array}{c}\text { IV } \downarrow \\
\longrightarrow(3,28: 2,96)\end{array}$ & $\mathrm{V}$ & VI \\
\hline & 2 & Tumbuh dan bina & $\begin{array}{l}\text { Pertahankan dan pelihara } \\
\text { (strategi tidak berubah) }\end{array}$ & $\begin{array}{c}\text { Panen atau divestasi } \\
\text { (kawasan terikat atau jual } \\
\text { habis kewaspadaan) }\end{array}$ \\
\hline & 1 & $\begin{array}{c}\text { VII } \\
\text { Pertahankan dan pelihara } \\
\text { (diversifikasi konsentrasi) }\end{array}$ & $\begin{array}{c}\text { VIII } \\
\text { Panen atau divestasi (diversifikasi } \\
\text { kongklomerasi) }\end{array}$ & $\begin{array}{c}\text { IX } \\
\text { Panen atau divestasi } \\
\text { (likuidasi) }\end{array}$ \\
\hline
\end{tabular}

Sumber: Hasil Penelitian (2020)

Posisi organisasi desa wisata Puspoardi berdasarakan nilai pembobotan saat ini berada pada titik koordinat matrik IFAS dan EFAS $=3,28: 2,96$. Titik dari total pembobotan ini menunjukkan posisi organisasi pada kuadaran I, artinya desa wisata Puspoardi berada pada posisi internal (IFAS) lebih kuat dibanding dengan posisi eksternalnya (EFAS), sehingga perlu menumbuhkan dan membina kembali strategi untuk pengembangan daya tarik wisata yang dapat mendukung proses pemasaran melalui keterbukaan untuk mendapatkan pendampingan dalam mengelola media promosi baik event kegiatan dan informasi serta peningkatan kemampuan sumberdaya manusia sebagai pengelola destinasi wisata.

Table 3 Matrik SWOT

\begin{tabular}{|c|c|c|}
\hline IFAS & STRENGHTS (S) : & WEAKNESESS (W) : \\
\hline & $\begin{array}{l}\text { 1. Kondisi landscape yang } \\
\text { indah } \\
\text { 2. Adanya embung yang } \\
\text { unik diatas bukit }\end{array}$ & $\begin{array}{l}\text { 1. Penyampaian informasi } \\
\text { melalui media online } \\
\text { kurang } \\
\text { 2. Penyampaian informasi }\end{array}$ \\
\hline
\end{tabular}

ISSN: 2355-6587, e-ISSN: 2528-2220

http://ejournal.bsi.ac.id/ejurnal/index.php/jp 


\begin{tabular}{|c|c|c|}
\hline EFAS & 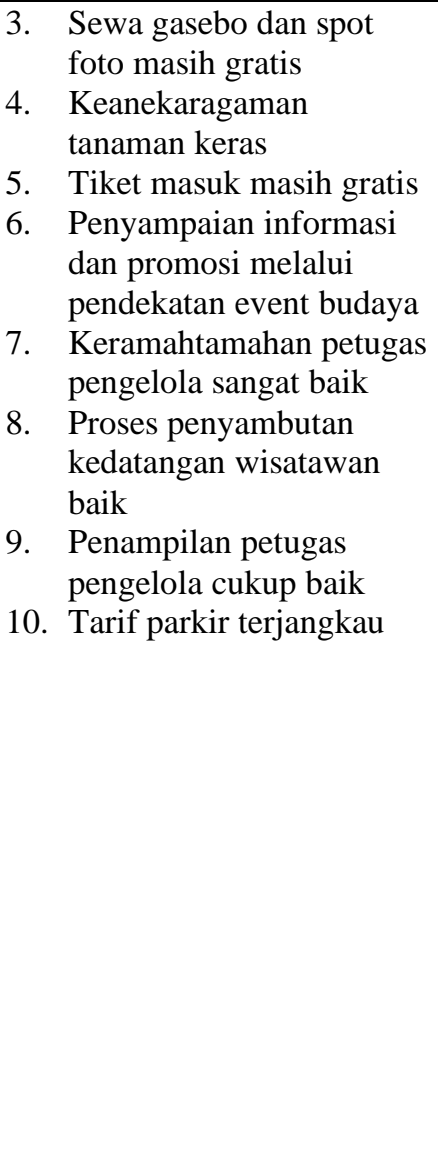 & $\begin{array}{l}\text { melalui media cetak } \\
\text { kurang } \\
\text { 3. Jalur/ rute yang dilalui } \\
\text { menuju objek wisata } \\
\text { kurang lebar } \\
\text { 4. } \begin{array}{l}\text { Fasilitas pendukung } \\
\text { yang tersedia (toilet) } \\
\text { belum ada }\end{array} \\
\text { 5. Program pendampingan } \\
\text { dan pelatihan bagi } \\
\text { pengelola masih kurang } \\
\text { 6. Peta jalan pengunjung } \\
\text { didalam lokasi belum } \\
\text { ada } \\
\text { 7. Pelayanan yang } \\
\text { diberikan kurang } \\
\text { maksimal } \\
\text { 8. Tempat parkir masih } \\
\text { terbatas } \\
\text { 9. Kemampuan SDM } \\
\text { perlu ditingkatkan baik } \\
\text { pengelolaan maupun } \\
\text { berkomunikasi dalam } \\
\text { bahasa asing }\end{array}$ \\
\hline OPPORTUNITIES (O) & STRATEGI S-O : & STRATEGI W-O : \\
\hline $\begin{array}{l}\text { 1. } \begin{array}{l}\text { Peran serta masyarakat } \\
\text { tinggi dalam }\end{array} \\
\text { pengembangan destinasi } \\
\text { 2. } \begin{array}{l}\text { Belum menerapan } \\
\text { teknologi informasi dalam } \\
\text { promosi dan pengelolaan }\end{array} \\
\text { 3. Didukung pemerintah desa } \\
\text { dalam pengembangannya } \\
\text { 4. Masih membutuhkan } \\
\text { sumber daya manusia yang } \\
\text { profesional } \\
\text { Mendapatkan bantuan } \\
\text { pemerintah secara } \\
\text { insidental } \\
\text { Masyarakat berperan aktif } \\
\text { dalam pengawasan objek } \\
\text { wisata } \\
\text { 7. Lokasi objek wisata } \\
\text { ditempat yang jauh dari } \\
\text { keramaian kota } \\
\text { 8. Pemandangan alam sekitar } \\
\text { sangat menarik } \\
\text { 9. Pengunjung dari berbagai } \\
\text { kalangan mayarakat lokal }\end{array}$ & 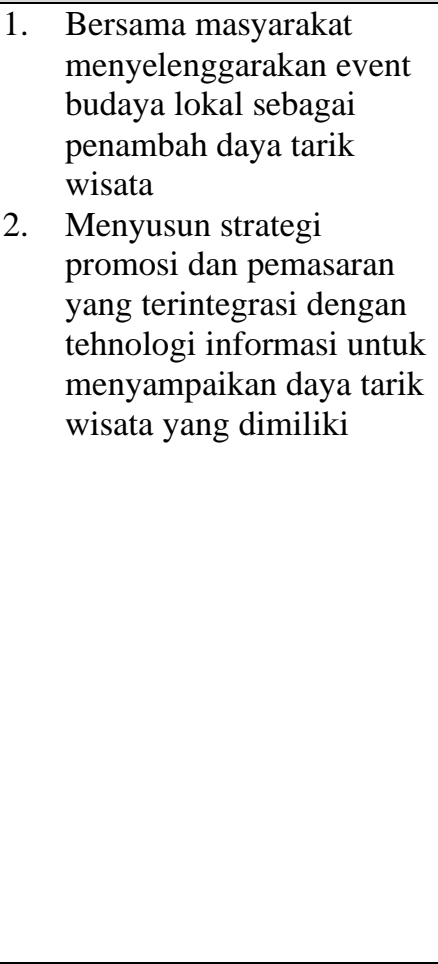 & 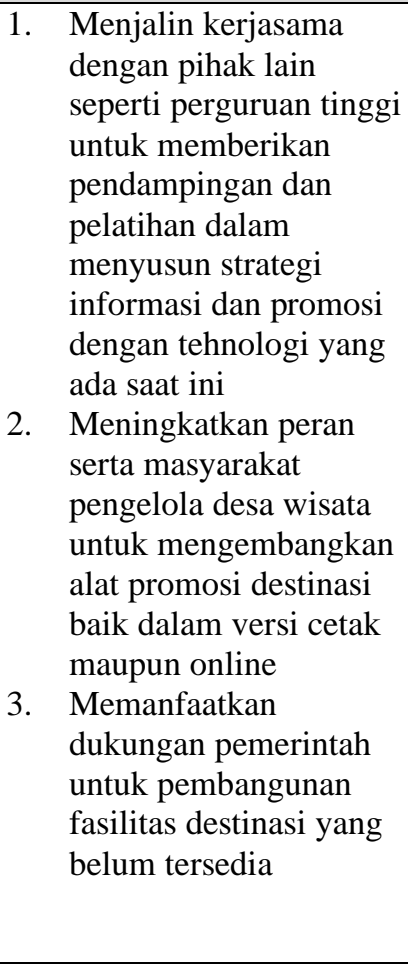 \\
\hline THREATS $(\mathrm{T})$ & STRATEGI S-T : & STRATEGI W-T : \\
\hline $\begin{array}{l}\text { 1. Motivasi pengunjung masih } \\
\text { kurang } \\
\text { 2. Keamanan pengunjung }\end{array}$ & 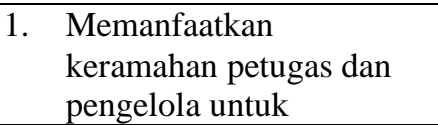 & 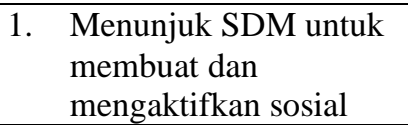 \\
\hline
\end{tabular}

ISSN: 2355-6587, e-ISSN: 2528-2220 


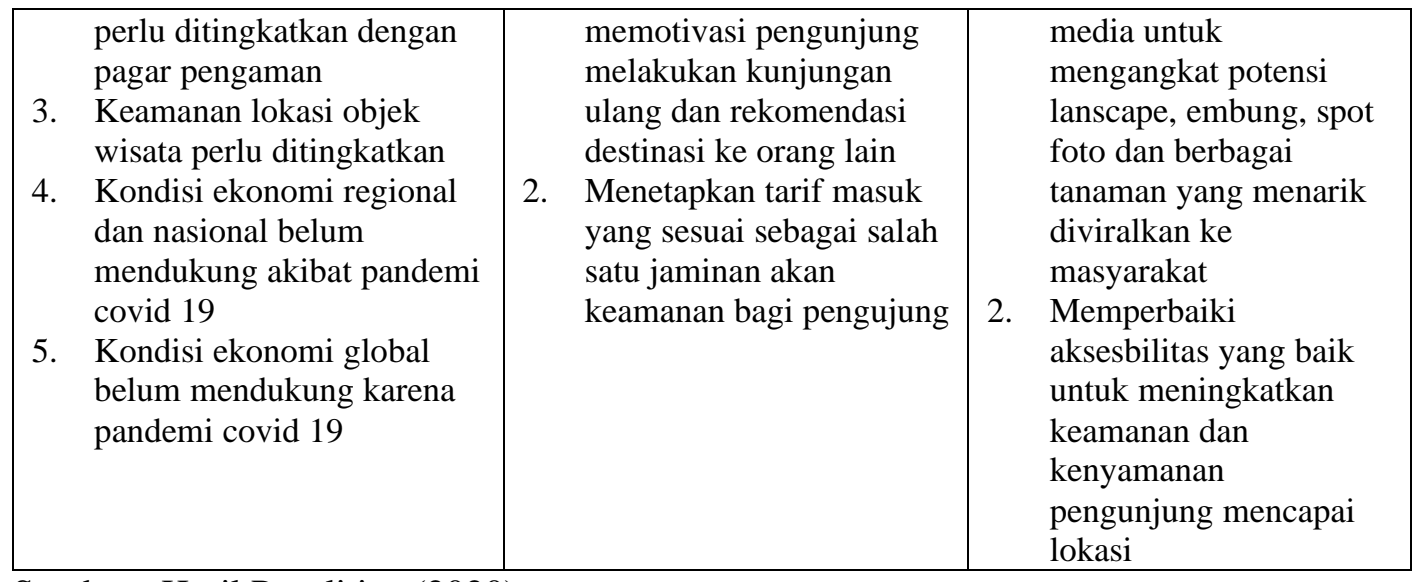

Sumber : Hasil Penelitian (2020)

Berdasarkan data pembobotan pada nilai IFAS dan EFAS pada tabel 1 dan tabel 2, dimana dari pembobotan tersebut dihasilkan nilai terbesar yang ada pada factor internal berupa kelemahan dan factor eksternal berupa peluang. Oleh karena itu strategi pengembangan daya Tarik wisata Puspoardi dalam jangka pendek dapat menerapkan strategi W-O, yaitu dengan (1) Menjalin kerjasama dengan pihak lain seperti perguruan tinggi untuk mendapatkan pendampingan dan pelatihan dalam menyusun strategi informasi dan promosi dengan tehnologi yang ada saat ini; (2) Meningkatkan peran serta masyarakat khususnya pengelola desa wisata untuk mengembangkan alat promosi yang relevan dalam versi cetak maupun online, (3) Memanfaatkan dukungan pemerintah untuk pembangunan pada fasilitas pokok yang belum tersedia..

Strategi pengembangan lain yang dapat diterapkan secara optional pada desa wisata Puspoardi dapat diuraikan, yaitu : untuk strategi S-O dengan (1) Bersama masyarakat menyelenggarakan event budaya lokal sebagai penambah daya tarik wisata; (2) Menyusun strategi promosi dan pemasaran yang terintegrasi dengan tehnologi informasi untuk menyampaikan daya tarik wisata yang dimiliki; untuk strategi S-T dengan (1) Memanfaatkan keramahan petugas dan pengelola untuk memotivasi pengunjung melakukan kunjungan ulang dan rekomendasi destinasi ke orang lain; (2) Menetapkan tarif masuk yang sesuai sebagai salah satu jaminan akan keamanan bagi pengujung. Sedangkan untuk strategi W-T dengan (1) Menunjuk SDM untuk membuat dan mengaktifkan sosial media untuk mengangkat potensi lanscape, embung, spot foto dan berbagai tanaman yang menarik diviralkan ke masyarakat; (2) Memperbaiki aksesbilitas yang baik untuk meningkatkan keamanan dan kenyamanan pengunjung mencapai lokasi.

\section{PENUTUP}

Strategi pengembangan daya tarik wisata untuk mendukung promosi pemasaran dalam jangka pendek berdasarkan analisis SWOT pada desa wisata Puspoardi adalah strategi dengan memanfaatkan segala kelemahan dan peluang (W-O) yang dirumuskan sebagai berikut: (1) Menjalin kerjasama dengan pihak lain seperti perguruan tinggi untuk mendapatkan pendampingan dan pelatihan dalam menyusun strategi informasi dan promosi dengan tehnologi yang ada saat ini; (2) Meningkatkan peran serta masyarakat khususnya pengelola desa wisata untuk mengembangkan alat promosi yang relevan dalam versi cetak maupun online, (3) Memanfaatkan dukungan pemerintah untuk pembangunan fasilitas pokok yang belum tersedia. Dengan ketiga rumusan ini pengelola dapat menyusun sub pokok rumusan untuk mewujudkan ketiga strategi tersebut. Sedangkan strategi lain yang sudah terumuskan dalam matrik

ISSN: 2355-6587, e-ISSN: 2528-2220

http://ejournal.bsi.ac.id/ejurnal/index.php/jp 
SWOT dapat menjadi strategi penunjang yang dapat diterapkan sesuai kebutuhan mendesak bagi pengelola desa wisata Puspoardi.

Penelitian ini tentunya tidak lepas dari kekurangan, karena dalam penelitian ini tidak melibatkan interaksi dengan pengunjung baik wawancara maupun questioner mengingat pendemi covid-19 saat penelitian, sehingga aspek kepuasan pengunjung pada desa wisata Puspoardi belum dapat digambarkan secara kualitatif.

\section{REFERENSI}

Adiyanto, Yoga; Supriatna, Yuda. 2018. Analisis Strategi Promosi Dalam Pengembangan Pariwisata Di Kabupaten Lebak Banten. Jurnal Sains Manajemen Volume. 4 No. 2 Tahun. 2018, Hal. 83-93.

Damanik, Janianton dan Weber, Helmut F. (2006). Perencanaan Ekowisata. Yogyakarta: Pusbar UGM \& Andi Yogyakarta

Damanik, Janianton. 2013. Pariwisata Indonesia. Yogyakarta: Pustaka Pelajar

Istifazhuddin, Alif Hazmi. 2016. Evaluasi pelaksanaan kebijakan ADD (alokasi dana desa) di desa Nguwok kecamatan Modo kabupaten Lamongan. Jurnal Kebijakan dan Manajemen Publik Volume 4, Nomor 2, MeiAgustus 2016, Hal. 315-326. Universitas Airlangga Surabaya.

Kartika, Titing; Ruskana, Rosman; Fauzi, Mohammad Iqbal. 2018. Strategi Pengembangan Daya Tarik Dago Tea House Sebagai Alternatif Wisata Budaya di Jawa Barat. The Journal : Tourism and Hospitality Essentials Journal, Vol. 8, No. 2, 2018, Hal. 121-138

Kotler, Philip, dan Gary Armstrong 2012. Prinsip-prinsip
Pemasaran. Edisi 13. Jilid 1. Erlangga : Jakarta

Kotler, Philip; Armstrong; Gary. 2012. Prinsip-prinsip Pemasaran. Edisi13. Jilid 1. Jakarta: Erlangga.

Kotler, Philip. 2000. Manajemen Pemasaran Jilid 2 Edisi Kesebelas. Jakarta: Prehallindo.

Mahendrayani, I Gusti Ayu Putu Seri; Suryawan, Ida Bagus. 2018. Strategi Pemasaran Daya Tarik Wisata Untuk Meningkatkan Jumlah Kunjungan Wisatawan Ke Daya Tarik Wisata Sangeh Kabupaten Badung Provinsi Bali. Jurnal Destinasi Wisata Vol.5 No.2 Tahun 2018, Hal.

Nainggolan, Deby Marlina; Kampana, I Made Adi. 2015. Strategi Pengembangan Pantai Sawangan Sebagai Daya Tarik Wisata Nusa Dua. Jurnal Destinasi Pariwisata Vol. 3 No 2 tahun 2015, Hal. 45-50.

Utama, I Gusti Bagus Rai \& Ni Made Eka Mahadewi. 2012. Metodologi Penelitian Pariwisata dan Perhotelan. Yogyakarta: ANDI.

Setiawan, Nisa Amalina; Hamid U, Farid. 2014. Strategi Promosi Dalam Pengembangan Pariwisata Lokal di Desa Wisata Jelekong. Jurnal Trikonomika Volume 13, No. 2, Desember 2014, Hal. 184194.

Setiyadi, Yudi. 2019. Pengertian Desa Wisata Dan Konsep Pengembangannya. 2019, Oktober 21. Diakses melalui : https://ensiklo.com/2019/10/21 /pengertian-desa-wisata/, 2 Februari 2021

Sistaningrum. 2002. Manajemen Promosi Pemasaran. Jakarta: Index.

Undang-Undang Republik Indonesia No.10. Tahun 2009 Tentang Kepariwisataan. Diakses melalui 
https://peraturan.bpk.go.id/Ho me/Details/38598/uu-no-10tahun-2009, 3 Desember 2020.

\section{BIODATA PENULIS}

Atun Yulianto, adalah dosen Universitas Bina Sarana Informatika Fakultas Ekonomi Dan Bisnis Program Studi Perhotelan. Dengan latar belakang Pendidikan ilmu manajemen. Tertarik pada penelitian bidang manajamen dan pemasaran. Mengampu pada mata kuliah manajemen pemasaran, akuntansi dan pengendalian biaya.

Emmita Devi Hari Putri adalah dosen Universitas Bina Sarana Informatika Fakultas Ekonomi Dan Bisnis Program Studi Perhotelan. Dengan latar belakang Pendidikan ilmu Kepariwisataan. Tertarik pada penelitian bidang pariwisata, kuliner dan parhotelan. Mengajar pada mata kuliah operasional patiseri dan pengolahan makanan. 